\title{
Regulation of postprandial mesenteric blood flow in humans: evidence for a cholinergic nervous reflex
}

\author{
C Sieber, C Beglinger, K Jaeger, P Hildebrand, G A Stalder
}

\begin{abstract}
Duplex ultrasound was used to investigate superior mesenteric artery haemodynamics in humans in order to determine the physiological importance of postprandial blood concentrations of cholecystokinin octapeptide (CCK8), gastrin 17, secretin, and glucagon and to study whether a nervous cholinergic reflex mechanism has a role in the postprandial mesenteric blood flow response. Duplex parameters of vessel diameter, mean velocity, and flow volume were determined serially in the basal state and after stimulation. Changes were compared with baseline values. Superior mesenteric artery parameters were significantly increased over baseline values after a liquid test meal, but ingestion of saline did not cause any changes. Hormones infused simultaneously at postprandial concentrations did not change mesenteric blood flow. When they were infused at pharmacological doses, however, a significant increase in flow parameters was observed. Pretreatment with atropine significantly $(\mathbf{p}<0.05)$ reduced the mesenteric blood flow response to meal stimulation (57\%). These data suggest that the four hormones tested are not of quantitative importance in regulating postprandial superior mesenteric artery blood flow. A cholinergic nervous reflex, however, participates in the control of food induced mesenteric artery flow changes.
\end{abstract}

Little is known about the regulatory mechanisms of human intestinal blood flow as our knowledge of intestinal circulatory dynamics is largely derived from animal studies. ${ }^{1-3}$ Previous methods of splanchnic blood flow measurement were invasive and demanding procedures, preventing their widespread application. Thus, only a few reports on human intestinal blood flow were published before $1984 . .^{48} \mathrm{An}$ increased awareness of the role of intestinal blood circulation in the pathogenesis of gastrointestinal diseases has led, however, to a greater emphasis on the development of techniques for measuring intestinal blood flow in humans.' Ultrasound combined with pulsed Doppler analysis (duplex scanning) for the non-invasive diagnosis of intestinal angina has recently been reported. ${ }^{10}$ The method is simple, non-invasive, and reproducible, and it can detect changes in mesenteric blood flow after physiological stimuli such as food intake. ${ }^{11-13}$

Many factors, including gastrointestinal hormones, have been implicated in the intestinal circulatory response to food. The studies carried out in animals show considerable variation between experiments and species. ${ }^{1+17}$ No data are available in man and an accurate assessment of the importance of specific gut hormones in intestinal haemodynamics is still needed.

The small intestine is extensively innervated by parasympathetic fibres originating from the vagi, $80-90 \%$ of them being afferent. ${ }^{18}$ Stimulation of vagal nerve endings has very little effect on intestinal blood flow. ${ }^{19}$ Stimulation of the intestinal mucosa of a denervated jejunal segment in cats, however, induced an increase in blood flow suggesting that local neural structures are involved in this response. ${ }^{20}$ Recent results in guinea pigs indicate that acetylcholine induces vasodilatation of arterioles in the small intestinal submucosal plexus. ${ }^{21}$ Again, no data are available in humans.

The primary objectives of this study were to assess the physiological importance of postprandial blood concentrations of cholecystokinin octapeptide (CCK8), secretin, gastrin 17, and glucagon on superior mesenteric artery blood flow and to determine whether a nervous reflex mechanism is involved in postprandial mesenteric artery blood flow in healthy humans. The superior mesenteric artery was chosen to assess intestinal blood flow because it supplies a large part of the small intestine, the right colon, and the pancreas and it is easily assessible for noninvasive measurement of blood flow.

\section{Methods}

\section{SUBJECTS}

Nine healthy male volunteers aged 21 to 27 years (mean 24 years) and with bodyweights averaging $66 \mathrm{~kg}$ (range $58-75 \mathrm{~kg}$ ) were studied in the morning after overnight fasting on different days and in random order. The investigations were carried out under resting conditions with the subjects lying in the supine position. Each subject was within $10 \%$ of his ideal body weight, none had a history of gastrointestinal or endocrine disorders, and none was taking any medication. All subjects gave written informed consent to the study, which was approved by the local Ethical Human Research Committee.

\section{DUPLEX TECHNIQUE}

Measurements of superior mesenteric artery blood flow were made using an ultrasonic duplex system consisting of a real time sector scanner (3.5 MHz) and a pulsed Doppler flowmeter (3.0 $\mathrm{MHz}$ (Diasonics DRF-400 CRV). The real time image allows visualisation of the artery. Anatomical variations can be detected and the diameter of the vessel can be measured. The B mode image is also used to adjust the sample volume of the pulsed Doppler beam and to 
ascertain the angle between the incident Doppler beam and the long axis of the vessel. ${ }^{10}$ The orientation of the Doppler beam, the Doppler angle, and the sample volume are electronically displayed on the screen. The Doppler signals are analysed by a real time spectrum analyser that uses a digital fast Fourier transform method. The analyser provides 100 spectra per second. The system then computes the time averaged velocity ( $\mathrm{cm} / \mathrm{second}$ ) from the average Doppler shift frequency and the angle between the beam and the vessel axis. The product of this mean velocity with the cross sectional area of the vessel lumen then yields the volume flow rate. To achieve accurate measurements, the vessel must follow a straight course for about $2 \mathrm{~cm}$ and no bifurcations should be present. ${ }^{12}$

In all studies, superior mesenteric artery blood flow was measured at 15 minute intervals, with measurements performed while the subjects held their breath. The superior mesenteric artery was identified and the diameter was measured 1 to 2 $\mathrm{cm}$ distally to the origin and proximally to the first side branches. The diameter measurement recording was ECG triggered - it was always undertaken at the same time in the cardiac cycle, before the pulsed Doppler beam that encompassed the vessel lumen was positioned. At each time point, three separate measurements of the diameter and the time averaged velocity were performed and the three determinations were averaged. The angle between the incident Doppler beam and the long axis of the vessel was kept at less than $65^{\circ}$. The time averaged velocity was computed from the 'envelope' of the Doppler spectra over three heart beats with the software of the duplex unit. In all studies, blood pressure and heart rate were monitored throughout the experiments.

EXPERIMENTAL DESIGN

The following experiments were performed in random order on seven non-consecutive days after a 45 minute basal period:

(1) Oral intake of a liquid test meal (Ensure plus, $500 \mathrm{ml}$, consisting of $31 \mathrm{~g}$ protein, $25 \mathrm{~g}$ fat, and $100 \mathrm{~g}$ carbohydrate with a total calorific value of $750 \mathrm{kcal}$ (equivalent to $3053 \mathrm{~kJ}$ )).

(2) Oral intake of $500 \mathrm{ml}$ iso-osmotic saline (442 $\mathrm{mOsm} / \mathrm{l}$ ).

(3) Intravenous infusion of a combination of synthetic CCK8 (20 ng/kg/hour), synthetic human secretin $(15.5 \mathrm{ng} / \mathrm{kg} /$ hour$)$, synthetic human gastrin $17(75 \mathrm{ng} / \mathrm{kg} /$ hour $)$, and synthetic human glucagon ( $500 \mathrm{ng} / \mathrm{kg} /$ hour), given for 60 minutes, followed by a 45 minute period of isotonic saline infusion. The doses above have previously been shown to produce postprandial blood concentrations of these peptides. ${ }^{22-25}$

(4) Infusion of pharmacological doses of the four peptides for 60 minutes (CCK8 $50 \mathrm{ng} / \mathrm{kg}$ ) hour; secretin $125 \mathrm{ng} / \mathrm{kg} /$ hour; gastrin 17500 $\mathrm{ng} / \mathrm{kg} /$ hour; glucagon $5000 \mathrm{ng} / \mathrm{kg} /$ hour) followed by a 45 minute infusion with isotonic saline.

(5) Before beginning basal measurements, the volunteers swallowed a double lumen duodenal tube with the tip of the tube lying near the ligamentum of Treitz. The tube was positioned under fluoroscopic control. In the 45 minute basal period, the duodenum was perfused with isotonic saline containing polyethyleneglycol 4000 as a non-absorbable marker (concentration $2 \mathrm{~g} / \mathrm{l}$ ) at a site between the second and third portion. After this control period, a liquid test meal (Ensure plus) containing polyethyleneglycol 4000 as a marker was perfused at a rate of $3 \mathrm{ml} /$ minute for 90 minutes followed by a 30 minute control period with saline. This perfusion rate should simulate the rate of gastric emptying. ${ }^{26}$ Gastric contents were continuously aspirated and the polyethyleneglycol 4000 concentration was measured in the pooled contents to estimate duodenal gastric reflux. In all experiments with duodenal intubation, polyethyleneglycol recovered from the stomach was always below $2 \%$ indicating negligible duodenal gastric reflux. A concomitant intravenous infusion of saline was given throughout the experiments.

(6) The same protocol was used as described in study 5 , but atropine sulfate was given instead of saline in a dose of $5 \mu \mathrm{g} / \mathrm{kg} / \mathrm{hour}$. This dose of atropine has previously been shown to have little effect on heart rate, but it inhibits stimulated exocrine pancreatic secretion in humans. ${ }^{27}$

(7) The duodenum was perfused with isotonic saline for 165 minutes.

\section{MATERIALS}

Synthetic CCK8, synthetic human secretin, and synthetic gastrin 17 were purchased from Peninsula Laboratories, Belmont, California. The peptides were dissolved in $0.9 \%$ saline containing $0.5 \%$ human serum albumin and prepared under aseptic conditions by the University of Basel Hospital Pharmacy. Vials were stored in ampoules at $-20^{\circ} \mathrm{C}$. Human glucagon was purchased from Novo AG, Zurich, Switzerland, and atropine sulfate from Sintetica Ltd, Mendrisio, Switzerland. Ensure plus was a kind gift of Abbott AG, Zug, Switzerland.

DATA ANALYSIS

The blood flow responses were expressed as percentages of the basal responses to normalise for any variations in basal mesenteric artery blood flow measurements. For each subject and each test, the area under the blood flow curve in response to stimulants over basal values was calculated. Group means and SEM were determined from these individual subject values and used for statistical analysis. The significance of differences between the areas under the curve were determined by $\mathrm{U}$ tests (Wilcoxon, MannWhitney). Differences were considered significant if $\mathrm{p}$ was $<0 \cdot 05$.

\section{Results}

\section{VESSEL DIAMETER}

\section{Oral test meal}

The mean diameter of the superior mesenteric artery in the preprandial state is given in Table $I$. As can be seen from these data, basal values did not differ significantly. After food intake, the 
TABLE I Diameter and mean blood flow velocity of the superior mesenteric artery in response to stimulants in six health subjects (values, mean SEM))

\begin{tabular}{|c|c|c|c|c|}
\hline & Fasting & $30 \mathrm{~min}$ & $60 \min$ & $90 \min$ \\
\hline \multicolumn{5}{|l|}{ Diameter $(\mathrm{cm})$ : } \\
\hline Oral test meal & $0.60(0.03)$ & $0.65(0.02)$ & $0.67(0.02)$ & $0.66(0.02)$ \\
\hline $\begin{array}{l}\text { Intravenous hormones } \\
\text { (high doses) }\end{array}$ & $0.59(0.01)$ & $0.63(0.01)$ & $0.63(0.01)$ & $0.60(0.01)$ \\
\hline $\begin{array}{l}\text { Intraduodenal test meal } \\
\text { with saline }\end{array}$ & $0.59(0.02)$ & $0.65(0.01)$ & $0.66(0.01)$ & $0.66(0.01)$ \\
\hline $\begin{array}{l}\text { Intraduodenal test meal } \\
\text { with atropine }\end{array}$ & $0.58(0.04)$ & $0.58(0.01)$ & $0.60(0.01)$ & $0.59(0.01)$ \\
\hline \multicolumn{5}{|l|}{ Mean velocity $(\mathrm{cm} / \mathrm{s})$ : } \\
\hline Oral test meal & $29 \cdot 8(5 \cdot 1)$ & $68 \cdot 4(11 \cdot 5)$ & $58 \cdot 7(6 \cdot 7)$ & $47 \cdot 7(5 \cdot 0)$ \\
\hline $\begin{array}{l}\text { Intravenous hormones } \\
\text { (high doses) }\end{array}$ & $33 \cdot 0(3 \cdot 9)$ & $48 \cdot 3(5 \cdot 5)$ & $43 \cdot 9(2 \cdot 7)$ & $38.9(4 \cdot 8)$ \\
\hline $\begin{array}{l}\text { Intraduodenal test meal } \\
\text { with saline }\end{array}$ & $32 \cdot 9(4 \cdot 3)$ & $65 \cdot 2(5 \cdot 0)$ & $63 \cdot 4(7 \cdot 2)$ & $63 \cdot 0(7 \cdot 8)$ \\
\hline $\begin{array}{l}\text { Intraduodenal test meal } \\
\text { with atropine }\end{array}$ & $29 \cdot 3(2 \cdot 0)$ & $43 \cdot 1(3 \cdot 1)$ & $50.6(1.6)$ & $51 \cdot 4(3 \cdot 7)$ \\
\hline
\end{tabular}

For each test and each subject the average of three separate determinations was used at each time point. Group means (SEM) were calculated from these individual responses.

diameter of the superior mesenteric artery increased significantly $(\mathrm{p}<0.05)$ and reached a maximum 60 minutes after food intake. This represents a $12 \%$ (range $5-26 \%$ ) increase over the initial values. Oral intake of $500 \mathrm{ml}$ of saline did not affect the diameter of the vessel (data not shown).

\section{Hormonal stimulation}

Low doses of simultaneously infused CCK8, secretin, gastrin 17, and glucagon did not affect the vessel diameter (data not shown). The higher doses of the four hormones, however, induced a small, but significant $(\mathrm{p}<0.05)$ increase in diameter of $8 \%$ (range $6-10 \%$ ) over basal values (Table I).

\section{Intraduodenal test meal}

The mean diameter of the superior mesenteric artery was compared in the three intraduodenal experiments. Intraduodenal perfusion of the test meal induced a significant $(p<0.05)$ maximal increase of $12 \%$ (range 5-19\%), reached 45 minutes after starting the meal perfusion (Table I). When the meal perfusion was stopped after 90 minutes, the mean diameter of the vessel

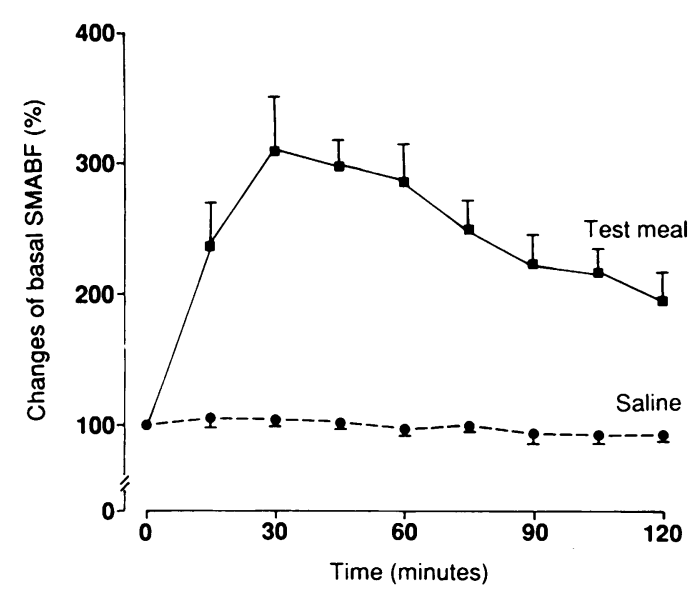

Figure 1: Doppler calculated volume flow through the superior mesenteric artery (SMABF) before and after intake of $500 \mathrm{ml}$ of a liquid test meal or of an equal amount of isoosmolar saline in six healthy subjects. Volume flow is expressed as percentage of the fasting value (mean (SEM)). Basal SMABF values were $443(38) \mathrm{ml} /$ minute and 526 (68) $\mathrm{ml} / \mathrm{minute}$ for the liquid meal and for saline, respectively. returned to the baseline value (mean 0.60 (SEM) $(0.01) \mathrm{cm}$ at the end of the experiment). Administration of atropine sulfate blocked the increase in the vessel diameter almost completely (Table I). Intraduodenal infusion of saline did not change the vessel diameter (data not shown).

\section{MEAN FLOW VELOCITY}

Oral test meal

The time averaged velocity of the superior mesenteric artery in the fasting state did not differ significantly in the various experiments and the data are given in Table I. Oral food intake induced a significant increase in the mean time averaged velocity $(p<0.01)$, reaching a maximum 30 minutes after eating. This velocity reflects a $130 \%$ (range $31-245 \%$ ) increase over the fasting value. The $500 \mathrm{ml}$ of saline did not affect the time averaged velocity (not shown).

\section{Hormonal stimulation}

The mean (SEM) fasting time averaged velocity was $33 \cdot 1(6 \cdot 2) \mathrm{cm} / \mathrm{second}$ in the experiment with low dose infusion of the four peptides. There was no significant change during administration of the four peptides at physiological doses $(34.8$ $(4 \cdot 1) \mathrm{cm} /$ second 30 minutes after starting the hormone infusion). Pharmacological doses of the four peptides, however, significantly $(p<0.05)$ increased the mean mesenteric velocity (Table I). This value after 30 minutes of infusion represents a $46 \%$ (range $18-79 \%$ ) increase over the fasting value $(\mathrm{p}<0 \cdot 05)$

\section{Intraduodenal test meal}

The mean mesenteric time averaged velocity during fasting and meal stimulated conditions (intraduodenal test meal), is given in Table I. At the time of maximal hyperaemia (45 minutes), the time averaged velocity was $104 \%$ (range $71-$ $184 \%$ ) higher than in the fasting state. After stopping the infusion, the mean velocity returned towards baseline values. Intraduodenal perfusion of isotonic saline did not alter the time averaged velocity (data not shown). Intravenous atropine sulfate hardly affected the maximal hyperaemic response (86\% (range 55-112\%) higher than in the fasting state), but it significantly delayed this increase (time to reach maximal time averaged velocity: 45 minutes in the control experiment versus 75 minutes in the atropine study, $\mathrm{p}<0.05)$.

\section{SUPERIOR MESENTERIC ARTERY BLOOD FLOW}

\section{Oral test meal}

During the basal period, the computed blood flow was 443 (38) $\mathrm{ml} / \mathrm{minute}$. After the test meal, there was an immediate, noticeable increase in mesenteric blood flow and a plateau was reached within 20 minutes of taking the meal (Fig 1). The maximum mesenteric blood flow was $250 \%$ higher than in the basal period (range 180 $360 \%$ ) and was reached within mean (SEM) 38 (8) minutes of eating. Sixty minutes after food 


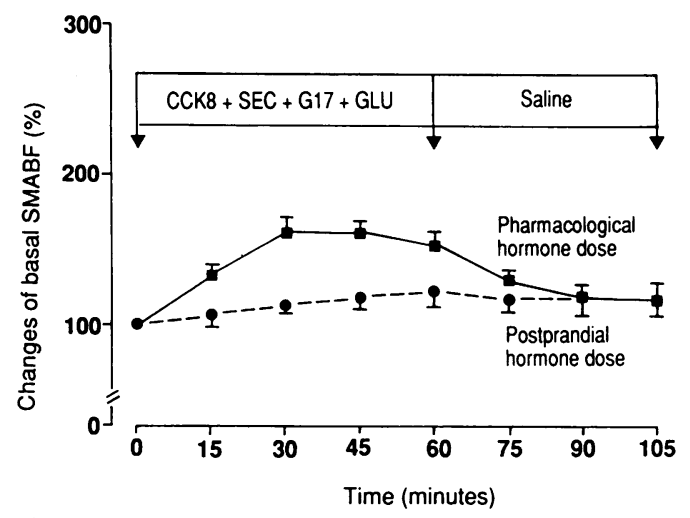

Figure 2: Superior mesenteric artery blood flow (SMABF) in response to a combination of cholecystokinin octapeptide (CCK8), secretin (SEC), gastrin $17(G 17)$, and glucagon (GLU) producing postprandial blood values in six healthy subjects. Also depicted is the SMABF response to the combined infusion of all four hormones at blood concentrations which are at least 10 times their respective postprandial concentrations. Volume flow is expressed as a percentage of the fasting value (mean (SEM)). Basal $S M A B F$ values were $468(65) \mathrm{ml} /$ minute and $545(59) \mathrm{ml}$ minute for low and high doses respectively.

intake the blood flow decreased slowly, but it was still significantly $(\mathrm{p}<0.01)$ above basal values at the end of the experiment. Oral intake of $500 \mathrm{ml}$ of saline, however, did not affect blood flow (Fig 1). The increase in the mesenteric blood flow after a meal was mainly due to an increase in velocity, the increase in the vessel diameter was less important.

\section{Superior mesenteric artery blood flow in response to hormonal stimulation}

Figure 2 summarises the observed effects on superior mesenteric artery blood flow of the simultaneous infusion of CCK8, secretin, gastrin 17, and glucagon in physiological and pharmacological concentrations. The low doses (producing postprandial plasma hormone concentrations) did not significantly alter mesenteric blood flow. Simultaneous infusion of all four hormones achieving blood values at least 10 times greater than their respective postprandial values, however, induced a significant mean

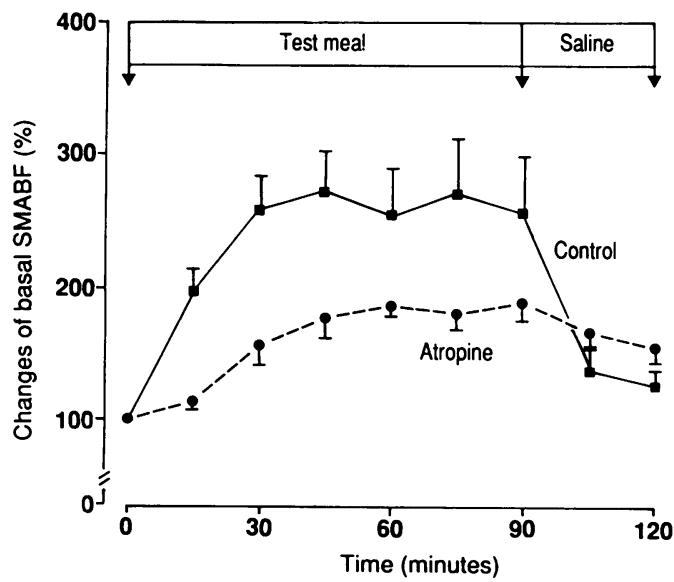

Figure 3: Superior mesenteric artery blood flow (SMABF) response to intraduodenal saline (control) or to an intraduodenal test meal with and without concomitant administration of intravenous atropine $(5 \mu \mathrm{g} / \mathrm{kg} / \mathrm{hour})$ in six healthy subjects. Doppler calculated volume flow is expressed as percentage of the fasting value (mean $(S E M))$. Basal as percentage of the fasting value (mean (SEM)). Basal
$S M A B F$ values were 520 (56) ml/minute and 453 (29) $\mathrm{ml} / \mathrm{minute}$ for the control and the atropine experiments respectively. increase (area under curve over 60 minutes) of mean (SEM) 53 (6)\% over control values $(p<0.05)$. At the end of the infusion, superior mesenteric artery blood flow returned towards the control value. The maximal mesenteric blood flow in response to these high doses of hormones was $72 \%$ (range $50-103 \%$ ) greater than the flow during the basal period. Again, the increase in mesenteric blood flow was mainly due to increases in velocity rather than diameter.

Comparison of superior mesenteric artery blood flow responses to oral food and hormonal stimulation The maximal increase in blood flow in response to the pharmacological doses of the four peptides was $21 \%$ (range $17-29 \%$ ) of the maximal blood flow response to food

\section{Effect of intraduodenal test meal on superior mesenteric artery blood flow}

Figure 3 shows the blood flow response to perfusion of the duodenum with a liquid test meal. Infusion of the test meal at a rate of $3 \mathrm{ml} /$ minute induced a significant increase $(\mathrm{p}<0.05)$ in superior mesenteric artery blood flow, reaching a plateau within 30 minutes of starting meal perfusion. The increase in blood flow was sustained during the meal perfusion, but declined sharply once this had stopped. Perfusion of isotonic saline at a rate of $3 \mathrm{ml} / \mathrm{minute}$ did not affect superior mesenteric arterial blood flow. Intravenous atropine sulfate, however, significantly reduced the response to intraduodenal test meal stimulation by $57 \%$ (range $49-61 \%$, $\mathrm{p}<0.01$ ). During treatment with atropine, an increase in heart rate was observed towards the end of the experiment compared with the control study (Table II). On the other hand, no difference was found in blood glucose concentrations in experiments with and without atropine (Table II).

\section{Discussion}

The present study can be summarised as follows:

(1) A liquid test meal induced a rapid increase in superior mesenteric artery blood flow, but ingestion of the same volume of saline was ineffective.

(2) A combination of intravenous CCK8, secretin, gastrin 17 , and glucagon at postprandial hormone concentrations did not significantly alter superior mesenteric blood flow. However, all four hormones given together at concentrations 10 times higher than those occurring after a meal significantly increased superior mesenteric artery blood flow.

(3) Intraduodenal perfusion of a test meal induced a significant increase in superior mesenteric artery blood flow which was partly blocked by concomitant atropine administration.

It is well established that after ingestion of a meal, a functional hyperaemia occurs in the splanchnic vascular bed. ${ }^{+611-13}$ The increase in intestinal hyperaemia generally peaks between 30 and 90 minutes after meal ingestion, but it may last for up to six hours depending on the nature of the meal. ${ }^{28}$ These observations are 
TABLE II Heart rate and blood glucose concentrations after intraduodenal test meal perfusion with and without atropine at rest and at different times after meal perfusion in six healthy subjects. Values, mean (SEM).

\begin{tabular}{|c|c|c|c|c|}
\hline \multirow[b]{2}{*}{ Time } & \multicolumn{2}{|c|}{ Intravenous saline (control) } & \multicolumn{2}{|c|}{ Intravenous atropine $(5 \mu \mathrm{g} / \mathrm{kg} / \mathrm{h})$} \\
\hline & $\begin{array}{l}\text { Heart rate } \\
\text { (beats/min) }\end{array}$ & $\begin{array}{l}\text { Glucose } \\
\text { (mmolll) }\end{array}$ & $\begin{array}{l}\text { Heart rate } \\
\text { (beats/min) }\end{array}$ & $\begin{array}{l}\text { Glucose } \\
\text { (mmolll) }\end{array}$ \\
\hline $\begin{array}{l}\text { Fasting } \\
15 \mathrm{~min} \\
60 \mathrm{~min} \\
90 \mathrm{~min}\end{array}$ & $\begin{array}{l}60(1) \\
59(1) \\
61(1) \\
63(1)\end{array}$ & $\begin{array}{l}3.8(0.2) \\
4.1(0.2) \\
4.4(0.4) \\
3.9(0.5)\end{array}$ & $\begin{array}{l}55(1) \\
54(3) \\
63(3) \\
69(4)\end{array}$ & $\begin{array}{l}3.6(0.2) \\
4.1(0.2) \\
4.3(0.1) \\
3.4(0.3)\end{array}$ \\
\hline
\end{tabular}

mostly based on data from animal studies as only a few reports on human beings have been published so far due to the technical problems associated with measuring intestinal blood flow in man. ${ }^{48}$ Transcutaneous ultrasonic duplex systems have recently been used to measure mesenteric blood flow after a meal. ${ }^{11-13}$ The technique has been described and discussed in detail. ${ }^{12}{ }^{13}$ Accurate measurements of blood flow velocities are possible with the duplex technique, provided that the angle of the incident Doppler beam in relation to the vessel axis is known. The combination of the $B$ mode scan (allowing accurate estimates of the diameter of the vessel of interest) with the Doppler unit allows correct determination of the Doppler angle, resulting in accurate velocity measurements. As shown before, the variations in basal values were small compared with the changes observed in various experimental conditions.

Data from this study confirm that mesenteric blood flow increases after food intake. ${ }^{11-13}$ The purpose of our study was, however, to gain further knowledge of the regulatory mechanisms involved in the control of postprandial mesenteric blood flow in man.

The role of gastrointestinal hormones as major humoral factors regulating intestinal blood flow during the postprandial phase is controversial. Data from animal studies are available for various peptides. Pharmacological effects of gastrin derived peptides have been studied in animals ${ }^{29} 30$ but no clear picture has emerged. Physiological concentrations of gastrin have not been investigated yet. High doses of exogenous secretin cause vasodilation in the small intestinal vascular system of the cat and the dog, ${ }^{15} 1731$ but secretin does not seem to be involved in the control of intestinal blood flow after a meal, as it is released in spikes and the very low concentrations observed postprandially do not affect intestinal blood flow. ${ }^{32-34}$ It is possible, however, that secretin interacts with other peptides, such as gastrin and CCK, as potentiating effects between secretin and these peptides have been shown in animals and humans. ${ }^{35} 36 \mathrm{CCK}$ derived peptides have vasodilatory effects, ${ }^{115} 17$ but the physiological importance of $\mathrm{CCK}$ as a regulator of intestinal blood flow has been challenged by Premen et al. ${ }^{17}$ Glucagon causes intestinal vasodilation in cats and increases superior mesenteric arterial blood flow in dogs. ${ }^{378}$ All these experiments were carried out with pharmacological rather than physiological doses and data in humans have not been published yet. The data from this study suggest the following:

(1) CCK8, secretin, gastrin 17, and glucagon at postprandial concentrations are not involved in the postprandial increase in superior mesenteric blood flow.

(2) All four hormones given together increase superior mesenteric artery blood flow significantly, but only at blood concentrations that are far higher than those occurring after a meal.

We conclude that the four peptides are not hormonal regulators of postprandial mesenteric blood flow, but we cannot exclude local paracrine effects of the four peptides participating in the regulation of superior mesenteric artery blood flow. This hypothesis was not addressed in the present investigation, but available evidence makes it rather unlikely.

The effects of atropine on meal stimulated mesenteric blood flow were rather unexpected. Firstly, when we planned this study no histological evidence was available that would have suggested direct cholinergic innervation of the mesenteric circulation. ${ }^{16}$ There is, however, recent experimental evidence for a direct cholinergic innervation of the submucosal vessels of the guinea pig. ${ }^{21}$ Secondly, direct stimulation of the vagal fibres does not induce intestinal vasodilation. $^{39}$ However, administration of acetylcholine induces intestinal vasodilation and increases intestinal motility ${ }^{18}$; both events can be observed after food, suggesting cholinergic participation in the regulation of mesenteric blood flow. In the present study, the test meal was perfused to the duodenum as atropine affects gastric emptying which would make it extremely difficult to interpret any observed change in blood flow. Here we observed a $57 \%$ reduction in arterial mesenteric blood flow in response to intraduodenal food stimulation after atropine administration, suggesting that cholinergic pathways participate in the control of postprandial mesenteric blood flow. Basal superior mesenteric artery blood flow, however, was not affected by atropine. A basic assumption from this conclusion is that atropine counteracts cholinergic activity only - an assumption that cannot be directly proved but which agrees with all known evidence on anticholinergic agents. Since, at the present time, we are unable to measure directly cholinergic activity, the administration of anticholinergic agents such as atropine provides a means of studying the influence of cholinergic activity on superior mesenteric artery blood flow. From the observed data, we suggest that a cholinergic nervous reflex participates in the control of postprandial mesenteric blood flow. There is some additional evidence for the existence of a nervous reflex as local anaesthetics applied topically to the intestinal mucosa appreciably inhibited or attenuated the local hyperaemic response to intrajejunal placement of food or glucose in cats. ${ }^{4041}$ Finally, stimulation of the intestinal mucosa of a denervated jejunal segment in cats induced an increase in blood flow again suggesting local neural reflexes. ${ }^{18}$

In conclusion, the present study confirmed that superior mesenteric artery blood flow increases significantly in response to food in man. The mechanisms involved have yet to be defined but we have shown that CCK8, secretin, gastrin 17 , and glucagon are unlikely to be involved as blood borne hormones. On the other hand, we were able to show that a cholinergic nervous 
reflex plays a role in the postprandial response of mesenteric hyperaemia. Further experiments are necessary to define the regulatory pathways of postprandial superior mesenteric artery blood flow in humans.

We thank Mrs Carita Frei for editorial assistance and for typing the manuscript. The study was supported by a grant from the Sando Foundation (to CS) and a grant from the Swiss National Science Foundation (grant 3.866-0.85).

Part of this study was presented at the American Gastroenterological Association Meeting (New Orleans, May 1988)

1 Donald DE. Splanchnic circulation. In: Shepherd JT, Abbond FM, eds. Handbook of physiology: the cardiovascular system (Volume 3). Baltimore, Maryland: Waverly Press Inc, 1983 : $219-40$.

2 Lundgren $\mathrm{O}$. Microcirculation in the gastrointestinal tract and pancreas. In: Renkin EM, Michel CC, eds. Handbook of pancreas. In: Renkin EM, Michel CC, eds. Handbook of physiology: the cardiovascular system (Volume

3 Granger DN, Kvietys PR, Korthuis RJ, Premen AJ. Microcirculation of the intestinal mucosa. In: Schultz SG, Wood JD Rauner BB, eds. Handbook of physiology: The gastrointestinal system (Volume 1). Baltimore, Maryland: Waverly Press Inc 1989: 1405-74.

4 Bradley SE, Ingelfinger FJ, Bradley GP, Curry JJ. Estimation of hepatic blood flow in man. 7 Clin Invest $1945 ; 24: 890-7$.

5 Brandt JL, Castleman L, Ruskin HD, Greenwald J, Kelly JJ. The effect of oral protein and glucose feeding on splanchnic blood flow and oxygen utilization in normal and cirrhotic blood flow and oxygen utilization in no

6 Norryd C, Dencker H, Lunderquist A, Olin T, Tylen U. Superior mesenteric blood flow during digestion in man Acta Chir Scand 1975; 141: 197-202.

7 Hulten L, Jodal M, Lindhagen J, Lundgren O. Colonic blood low in cat and man as analyzed by an inert gas washou technique. Gastroenterology 1976; 70: 36-44

8 Hulten L, Jodal M, Lindhagen J, Lundgren O. Blood flow in the small intestine of cat and man as analyzed by an inert gas washout technique. Gastroenterology 1976; 70: 45-51.

9 Granger DN, Kvietys PR. Recent advances in measurement of gastrointestinal blood flow. Gastroenterology 1985; 88: 1073 gastr.

10 Jäger KA, Fortner GS, Thiele BL, Strandness Jr DE. Noninvasive diagnosis of intestinal angina. $\mathscr{C} C U$ 1984; 12: 58891.

11 Qamar MI, Read AE, Skidmore R, Evans JM, Wells PNT Transcutaneous Doppler ultrasound measurement of superior mesenteric artery blood flow in man. Gut 1986; 27 $100-5$.

12 Jäger K, Bollinger A, Valli C, Ammann R. Measurement of mesenteric blood flow by duplex scanning. 7 Vasc Surg 1986 3: 462-9.

13 Moneta GL, Taylor DC, Helton WS, Mulholland MW, Strandness DE. Duplex ultrasound measurement of postprandial intestinal blood flow: Effect of meal composition. prandial intestinal blood flow: Effect

14 Fara JW, Madden KS. Effects of secretin and cholecystokinin on small intestinal blood flow distribution. Am 7 Physio 1975; 229: 1365-70.

15 Chou CC, Hsieh CP, Dabney JM. Comparison of vascular effects of gastrointestinal hormones on various organs. $A m \mathcal{F}$ Physiol 1977; 232: H103-9.

16 Chou CC. Relationship between intestinal blood flow and motility. Annu Rev Physiol 1982; 44: 29-42.

17 Premen AJ, Kvietys PR, Granger DN. Postprandial regulation of intestinal blood flow: role of gastrointestinal hormones. Am F Physiol 1985; 249: G250-5.

18 Kewenter J. The vagal control of the jejunal and ileal motility and blood flow. Acta Physiol Scand (Suppl 251) 1965; 65: 1-
19 Fara JW, Rubinstein EH, Sonnenschein RR. Intestinal hormones in mesenteric vasodilation after duodenal agents. Am F Physiol 1972; 223: 1058-67.

20 Biber B, Fara J, Lundgren O. A pharmacological study of intestinal vasodilator mechanisms in the cat. Acta Physio Scand 1974; 90: 673-83.

21 Neild TO, Shen KZ, Surprenant A. Vasodilatation of arterioles by acetylcholine released from single neurons in the guinea-pig submucosal plexus. F Physiol 1990; 420: 24765

22 Beglinger C, Fried M, Whitehouse I, Jansen JB, Lamers CB, Gyr K. Pancreatic enzyme response to a liquid meal and to hormonal stimulation. Correlation with plasma secretin and cholecystokinin levels. 7 Clin Invest 1985; 75: 1471-6.

23 Christ A, Werth B, Hildebrand P, Gyr K, Stalder GA, Beglinger C. Human secretin. Biologic effects and plasma kinetics in humans. Gastroenterology 1988; 94: 11-6.

24 Blair AJ, Feldman M, Barnett C, Walsh JH, Richardson CT Detailed comparison of basal and food-stimulated gastric acid secretion rates and serum gastrin concentrations in duodenal ulcer patients and normal subjects. 7 Clin Inves 1987; 79: 582-7.

25 Loud FB, Froberg D, Reichardt J, Holst JJ, Rehfeld JF Christiansen J. Inhibition of meal-stimulated gastric acid secretion in man by exogenous and endogenous pancreatic glucagon. Scand $\mathcal{F}$ Gastroenterol 1978; 13: 795-8.

26 Malagelada JR, Go VLW, Summerskill WHJ. Differen gastric, pancreatic, and biliary responses to solid-liquid or homogenized meals. Dig Dis Sci 1979; 24: 101-10.

27 Adler G, Reinshagen M, Koop I, et al. Differential effects of atropine and a cholecystokinin receptor antagonist on pancreatic secretion. Gastroenterology 1989; 96: 1158-64.

28 Fara JW. Postprandial mesenteric hyperemia. In: Shepherd AP, Granger DN, eds. Physiology of the intestinal circulation. New York: Raven, 1984: 99-106.

29 Wormsley KG, Mahoney MP, Ng M. Effects of a gastrinlike pentapeptide (ICI 50123) on stomach and pancreas. Lancet 1966; ii: 993-9.

30 Fasth S, Filipsson S, Hulten L. The effect of the gastrointestinal hormones on small intestinal motility and blood flow. Experientia 1973; 29: 982-4.

31 Richardson PDI. The actions of natural secretin on the smal intestinal vasculature of the anaesthetized cat. $\mathrm{Br} f$ Pharmacol 1976; 58: 127-35.

32 Pelletier MJ, Chayvialle JAP, Minaire Y. Uneven and transient secretin release after a liquid test meal. Gastrotransient secretin release af
enterology $1979 ; 75: 1124-32$.

33 You CH, Rominger JM, Chey WY. Effects of atropine on the action and release of secretin in humans. Am $\mathcal{F}$ Physiol 1982 242. G608-11.

34 Gyr K, Beglinger C, Fried M, et al. Plasma secretin and pancreatic response to various stimulants including a meal. Am F Physiol 1984; 246: G535-42.

35 Beglinger C, Grossman MI, Solomon TE. Interaction between stimulants of exocrine pancreatic secretion in dogs. $A m$ Physiol 1984; 246: G173-9.

36 You CH, Rominger JM, Chey WY. Potentiation effect of cholecystokinin-octapeptide on pancreatic bicarbonate secretion stimulated by a physiologic dose of secretin in secretion stimulated by a physiologic dose
humans. Gastroenterology 1983; 85: 40-5.

37 Richardson PDI. The effects of glucagon and pentagastrin on capillary filtration coefficient in the innervated jejunum of the anaesthetized cat. Brf Pharmacol 1975; 54: 225P.

38 Ross G. Regional circulatory effects of pancreatic glucagon. $B$ f Pharmacol 1970; 38: 735-42.

39 Shehadeh Z, Price WE, Jacobson ED. Effects of vasoactive agents on intestinal blood flow and motility in the dog. Am Physiol 1969; 216: 386-92.

40 Biber B, Lundgren O, Svanvik J. Studies on the intestina vasodilation observed after mechanical stimulation of the mucosa of the gut. Acta Physiol Scand 1971; 82: 177-90.

41 Chou CC, Burns TD, Hsieh CP, Dabney JM. Mechanisms of local vasodilatation with hypertonic glucose in the jejunum. Surgery 1972; 71: 380-87. 